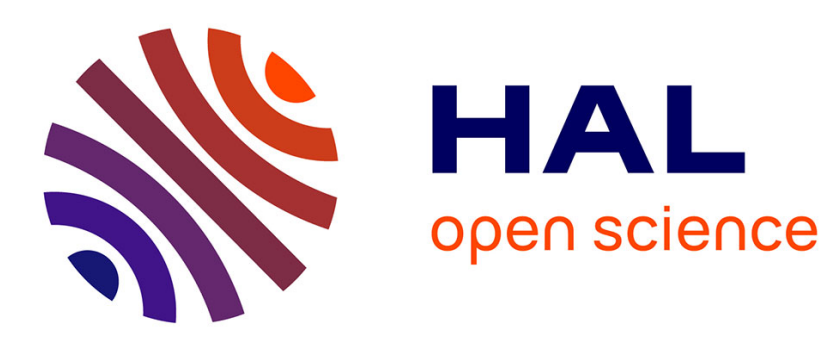

\title{
Phase transitions in CsHSO4 up to 2.5GPa: Impedance spectroscopy under pressure
}

Nikolai Bagdassarov

\section{To cite this version:}

Nikolai Bagdassarov. Phase transitions in CsHSO4 up to 2.5GPa: Impedance spectroscopy under pressure. Journal of Physics and Chemistry of Solids, 2011, 72 (4), pp.236. 10.1016/j.jpcs.2011.01.008 . hal-00727163

\section{HAL Id: hal-00727163 \\ https://hal.science/hal-00727163}

Submitted on 3 Sep 2012

HAL is a multi-disciplinary open access archive for the deposit and dissemination of scientific research documents, whether they are published or not. The documents may come from teaching and research institutions in France or abroad, or from public or private research centers.
L'archive ouverte pluridisciplinaire HAL, est destinée au dépôt et à la diffusion de documents scientifiques de niveau recherche, publiés ou non, émanant des établissements d'enseignement et de recherche français ou étrangers, des laboratoires publics ou privés. 


\section{Author's Accepted Manuscript}

Phase transitions in CsHSO4 up to 2.5GPa: Impedance spectroscopy under pressure

Nikolai Bagdassarov

PII:

DOI:

Reference:

S0022-3697(11)00018-7

doi:10.1016/j.jpcs.2011.01.008

PCS 6395

To appear in:

Journal of Physics and

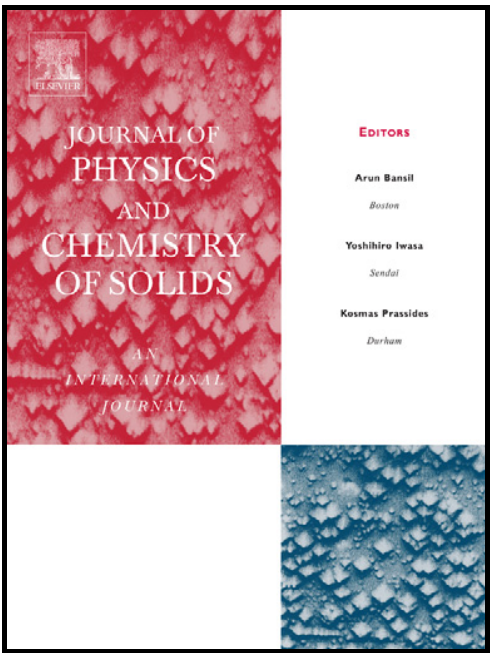

www.elsevier.com/locate/jpcs Chemistry of Solids

Received date: 17 May 2010

Revised date: $\quad 30$ November 2010

Accepted date: 13 January 2011

Cite this article as: Nikolai Bagdassarov, Phase transitions in CsHSO4 up to 2.5GPa: Impedance spectroscopy under pressure, Journal of Physics and Chemistry of Solids, doi:10.1016/j.jpcs.2011.01.008

This is a PDF file of an unedited manuscript that has been accepted for publication. As a service to our customers we are providing this early version of the manuscript. The manuscript will undergo copyediting, typesetting, and review of the resulting galley proof before it is published in its final citable form. Please note that during the production process errors may be discovered which could affect the content, and all legal disclaimers that apply to the journal pertain. 


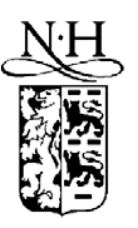

Journal logo

\title{
Phase transitions in $\mathrm{CsHSO}_{4}$ up to $2.5 \mathrm{GPa}$ : Impedance spectroscopy under pressure
}

\author{
Nikolai Bagdassarov ${ }^{*}, 1$ \\ ${ }^{1}$ Institute for Geosciences, Goethe-University in Frankfurt am Main, Altenhöferallee 1, D-60438, Germany
}

Elsevier use only: Received date here; revised date here; accepted date here

\begin{abstract}
Phase transitions in $\mathrm{CsHSO}_{4}$ at pressures up to $2.5 \mathrm{GPa}$ have been studied with the help of electrical impedance measurements. The phase boundaries have been identified with the help of calculated activation energies of electrical conductivity and dielectric relaxation time. The derived temperatures of phase transition from the low conductive phase II into super ionic phase I at pressure less than $1 \mathrm{GPa}$ confirm the previous results of Ponyatovskiy et al. (1985) and Friesel et al. (1989). The phase diagram derived in this study for pressure larger than $1 \mathrm{GPa}$ differs from the data of Ponyatovskiy et al. (1985). The phase transitions IV-VI and VI-I occur at higher temperatures having significantly larger Clapeyron slope. The phase VII was not identified from heating cycle and appears only under cooling between phase I and phase VI. The phase VIII was detected at $2.5 \mathrm{GPa}$ at $\mathrm{T}<350 \mathrm{~K}$ and only during heating cycle. (c) 2001 Elsevier Science. All rights reserved
\end{abstract}

Key words: ionic conductivity; $\mathrm{CsHSO}_{4}$; phase transitions; impedance spectroscopy;

PACS: PACS 71.30.+h, 72.20.Ee, 72.80.Jc, 74.62.-c 74.62.Fj

\footnotetext{
* Corresponding author: e-mail nickbagd@geophysik.uni-frankfurt.de, Phone: +49 69798 40126, Fax: +49 6979840131
} 
1 Introduction During the last two decades there is a growing interest to fast protonic conductors because of their potential applications in fuel cells, gas sensors, hydrogen/water reactors etc $[1,2]$. $\mathrm{CsHSO}_{4}$ crystals represents a special interest among other fast protonic conductors due to their highest conductivity in the high temperature phase [3-6], which possesses protonic electrical conductivity because of the enhanced translational mobility of protons above the phase transition temperature, $\mathrm{T}>$ $\mathrm{T}_{\mathrm{c}}$. The phase transition temperature $\mathrm{T}_{\mathrm{c}}$ corresponds to the phase boundary between the monoclinic, low temperature phase II $\left(P{ }_{1} / c\right)$, and the tetragonal, high temperature phase $\mathrm{I}\left(\right.$ I $4_{1} /$ amd $) . \mathrm{T}_{\mathrm{c}}$ has been determined at the atmospheric pressure 413 - $414 \mathrm{~K}$ according to $[3,6,7], 415 \mathrm{~K}$ [8], 416K [9-11] and $417 \mathrm{~K}$ [5]. Different methods used to identify this phase transition temperature resulted in small variations of $\mathrm{T}_{\mathrm{c}}$ : $413 \mathrm{~K}$ according to electrical conductivity measurements and 417 - 419K according to DSC data $[12,13]$. There are only few experimental works dealing with determination of $T_{c}$ at pressure. In $[10,14]$ the DTA method has been realized at pressures up to $0.9 \mathrm{GPa}$. Today, the consensus exists on the low pressure part of the phase diagram $\mathrm{CsHSO}_{4}$ at $\mathrm{P}<0.9 \mathrm{GPa}[4,10,14]$. The measurements indicate a small positive slope of Clapeyron slope of this phase boundary from $5 \mathrm{~K} / \mathrm{GPa}$ [4] to $12.6 \mathrm{~K} / \mathrm{GPa}$ [14]. The phase diagram at higher pressures (up to $2 \mathrm{GPa}$ ) has been explored only once in [4] using a constant frequency AC-electrical conductivity measurements and piezometry. To the author knowledge this is only one publication of the phase diagram $\mathrm{CsHSO}_{4}$ at high pressures which was estimated about 25 years ago. The phase diagram of $\mathrm{CsHSO}_{4}$ has been widely exploited in many theoretical studies and some new high pressure polymorphs of $\mathrm{CsHSO}_{4}$ have been predicted, but the high pressure - high temperature results of [4] have not been reproduced or verified experimentally. As a matter of fact in [4] the measured Clapeyron slope of the phase transition I-II below $1 \mathrm{GPa}$ corresponds to the entropy change $\Delta \mathrm{S}=82 \mathrm{~J} / \mathrm{mol} / \mathrm{K}$, which is 5 times larger than the later experimentally measured and theoretically calculated $\Delta \mathrm{S}=12-15 \mathrm{~J} / \mathrm{mol} / \mathrm{K}$ for this phase boundary [15]. The data of $[4,14]$ indicate a small thermal hysteresis (c. 4K) of the phase transition in superprotonic phase I at $\mathrm{P}<1 \mathrm{GPa}$. The results of [4] at higher pressures indicate no thermal hysteresis although that the phase transition II-I is the pronounced first order of the phase transition and the thermal hysteresis should not be negligible.

In the present study the impedance spectroscopy (IS) method has been implemented to measure the bulk ionic electrical conductivity of $\mathrm{CsHSO}_{4}$ at pressures up to $2.5 \mathrm{GPa}$. The implied impedance spectroscopy and the results which obtained in this study provide not only specific resistance of the studied sample, but also the dielectric relaxation time of $\mathrm{CsHSO}_{4}$ different polymorphs which has not been reported before.

\section{Experiments}

2.1 Sample preparation The crystals of $\mathrm{CsHSO}_{4}$ have been synthesised by slow evaporation of a mixture with molar ratio $1: 1$ of $\mathrm{Cs}_{2} \mathrm{SO}_{4}$ and $\mathrm{H}_{2} \mathrm{SO}_{4} 1 \mathrm{M}$-water solutions over 14 days. The crystals of $\mathrm{CsHSO}_{4}$ have been dried and ground to a fine powder with c. 20-30 $\mu \mathrm{m}$ of grain size. The purity of the starting and the recovered after high pressure experiments polycrystalline materials was checked with X-ray diffraction. No phases other than the low temperature monoclinic phase of $\mathrm{CsHSO}_{4}$ have been detected in starting and recovered samples.

2.2 Impedance measurements The main difference of the present study from previous determinations of the phase transition temperatures in $\mathrm{CsHSO}_{4}$ consists in the use of the impedance spectroscopy method at high pressures. The description and the calibration of the high pressure press and impedance measurements have been done elsewhere [16]. In this study a conventional end loaded piston-cylinder apparatus was used with a pressure cell consisting of $\mathrm{CaF}_{2}$, as a confining medium, $\mathrm{MgO}$ insulation sleeve and the graphite sleeve as a heater [16]. The experiments have been carried out at pressures from 0.5 to $2.5 \mathrm{GPa}$ and temperatures from 300 to $600 \mathrm{~K}$. Additional experimental run has been conducted by using unloaded press at $0.1 \mathrm{MPa}$. The pressure calibration of the cell has been done by the use of some standard point materials: at room temperature the transformations $\mathrm{Bi}$ I-II-III at 2.56 and $2.7 \mathrm{GPa}$ have been used; at high pressure the melting curves of $\mathrm{NaCl}$ and $\mathrm{CsCl}$ have been exploited. The melting points of these salts as a function of pressure up to 2.5 GPa has been determined in-situ by electrical conductivity measurements. The performed pressure calibration is believed to be within an accuracy of \pm $30 \mathrm{MPa}$. For temperature measurements the S- (at 
high pressures) and T-types (at low pressures) of thermocouple have been used. The temperature gradient in the cell has been estimated on $\mathrm{CsHSO}_{4}$ powder samples by the use of two thermocouples located at two different distances from the centre of the high pressure cell. The estimation of the radial temperature gradient is ca. $2-2.5 \mathrm{~K} / \mathrm{mm}$, the vertical temperature gradient is ca. $0.5 \mathrm{~K} / \mathrm{mm}$ in the temperature range up to $600 \mathrm{~K}$. The constant pressure was provided by a servomotor which regulated the position of the piston with the help of an additional hydraulic cylinder. The oil pressure in loading hydraulic rams was maintained within $\pm 0.05 \mathrm{MPa}$. Movement of the compressing piston in the autoclave was monitored with the LVDT having precision \pm $0.001 \mathrm{~mm}$.

The electrical impedance measurements have been performed with the use of Solartron ${ }^{\circledR} 1260$ PhaseGain-Analyzer interfaced with PC. In the case of high resistance $(>10 \mathrm{M} \Omega)$ the PSM 1700 Impedance Analysis Interface with the special fixture TA107 from N4L® has been used. The complex impedance data have been proceed with the help of Novocontrol software packages WinDeta and Win Fit

The high pressure cell for the electrical impedance measurements represents a coaxial cylindrical capacitor with a geometric factor $G=4.5-6.5 \cdot 10^{-2} \mathrm{~m}$ filled with a pressed powder sample. The exact geometric factor of a cell has been evaluated as a function of frequency in calibration measurements using $\mathrm{NaCl}$ solutions $(0.01 \mathrm{M}-3 \mathrm{M})$ at $300 \mathrm{~K}$ and pressure 0.1 MPa [16].

During the impedance measurements the press was isolated from the ground of Phase-Gain Analyser Solartron 1260. One of the thermocouple wires and the mass of the high pressure autoclave were used to connect the measuring device and the cell electrodes. Before doing the high pressure experiments a measuring cell has been calibrated for a short and for open circuit impedances in the frequency range from $1 \mathrm{MHz}$ to $0.01 \mathrm{~Hz}$. A typical AC-resistance of the cell in a short circuit is $\sim 0.4 \Omega$. These calibrations have been taken into account in final calculations of the electrical impedance as a function of frequency. Each frequency scan of the complex resistance has been fitted to the expression as follows (e.g. [17]):

$$
Z^{*}=\frac{R_{1}}{1+\left(j \cdot \omega \cdot \tau_{1}\right)^{p}}+\frac{R_{2}}{1+\left(j \cdot \omega \cdot \tau_{2}\right)^{n}}
$$

, where the first and the second terms are responsible for high and low frequency dielectric losses, i.e. to two arcs on an Argand-type of diagram describing bulk conductivity and electrode polarization processes. In the case of the three arcs the third term has been added to Eq 1. Parameters $\tau_{l}, R_{l}$ and $p$ are related to the bulk properties of a sample, $\tau_{2}, R_{2}$ and $n$ are related to the sample-electrode polarization. The bulk DC-conductivity of a sample is calculated from AC-measurements $\sigma_{D C}=\frac{1}{\boldsymbol{R}_{\mathbf{1}} \cdot \boldsymbol{G}}$, where $G$ is the geometric factor of electrodes. The temperature dependence of the bulk DC-conductivity usually follows an Arrhenius-type of dependence

$\sigma_{D C} \cdot T=\sigma_{0} \cdot e^{-\frac{E_{\sigma}}{k T}}$

, where $\sigma_{0}$ is the pre-exponential factor, $E_{\sigma}$ is the activation energy of the electrical conductivity, characterizing an energetic barrier for the movement of charge carriers, $i$. e. lattice defects. The parameter $p$ in Eq 1 describes a power law dispersion in a situation when the short range displacements of lattice defects become coupled with ionic environment. In ionic conductors with the increasing temperature, $p$ may decrease from $\sim 1$ to $0.5-0.6$ [18]. In different temperature intervals the accuracy of the fitting parameters for the first or for the second terms in the right hand side of Eq 1 varies significantly. Thus, $n, \tau_{2}$ and $R_{2}$ in Eq 2 were not used in analysis of the experimental data.

The bulk dielectric relaxation time $\tau_{l}=\tau$ depends on the temperature also according to an Arrhenius -type of equation as follows

$\tau=\tau_{0} \cdot e^{-\frac{E_{\tau}}{k T}}$

, where $\tau_{0}$ is the pre-exponential factor and $E_{\tau}$ is the activation energy of the dielectric relaxation time. $E_{\tau}$ corresponds to the activation energy of a peak of the imaginary component of electric impedance.

2.3 Results of measurements The results of ionic electric conductivity of measurements at 0.1 $\mathrm{MPa}, 0.5$ and $0.75 \mathrm{GPa}$ are presented in Figs. 1 as a graph $\ln (\sigma x T)$ vs. $1 / T$. The sample measured at 0.1 $\mathrm{MPa}$ has been pre-compressed at $1 \mathrm{GPa}$ at room temperature, and then decompressed to $0.1 \mathrm{MPa}$ 
during c. 72 hours. Fig. 2 demonstrates the Arrhenius dependence of the dielectric relaxation time $\tau$ vs $1 / T$. The results of ${ }^{1} \mathrm{H}$ MAS NMR [19] for mean residence time $\tau_{\mathrm{H}}$ are shown here for comparison as a solid arrow. The main drop of electric conductivity, of dielectric relaxation time and of mean residence time of ${ }^{1} \mathrm{H}$ corresponds to the phase transition from phase II (ferroelastic phase) to phase I (superprotonic phase). Here we use the conventional nomenclature of phases taken from [7, 10, 11], which is traditionally used for $\mathrm{CsHSO}_{4}$ polymorphs. The range of dielectric relaxation times in phase III and II corresponds within one order of magnitude to the range of the mean residence time from ${ }^{1} \mathrm{H}$ MAS NMR [19]. At temperature above $\mathrm{T}_{\mathrm{c}}=\mathrm{T}_{\text {II-I }}$ transition the dielectric relaxation time cannot be derived from the electrical impedance measurements. The range of dielectric relaxation times as well as the $\mathrm{T}_{\text {III-II }}$ transition depends weakly on pressure from $0.1 \mathrm{MPa}$ to $0.75 \mathrm{GPa}$ (Fig. 2). The dielectric relaxation time on pressure at constant temperature increases within 1 order of magnitude from $0.1 \mathrm{MPa}$ to $0.75 \mathrm{GPa}$. The slope of the temperature dependence of dielectric relaxation time on heating at $0.1 \mathrm{MPa}, 0.5 \mathrm{GPa}$ and $0.75 \mathrm{GPa}$ is about the same as for the temperature dependence of the mean relaxation time of protons $\left(\tau_{H}\right)$ estimated from NMR [19]. The absolute values of dielectric relaxation time $\tau$ during heating are less than $\tau_{\mathrm{H}}$ for about 1 order of magnitude at $0.1 \mathrm{MPa}$, and 0.5 orders of magnitude at 0.5 and $0.75 \mathrm{GPa}$. During cooling the dielectric relaxation time has higher activation energy than $\tau_{H}$ but the values of $\tau$ tend to $\tau_{\mathrm{H}}$ at room temperature (Fig. 2). The absolute value of electrical conductivity measured at $0.1 \mathrm{MPa}$ and $400 \mathrm{~K}$ is $210^{-4} \mathrm{~S} / \mathrm{m} \cdot \mathrm{K}$ during heating and $3.4 \cdot 10^{-4}$ $\mathrm{S} / \mathrm{m}^{\cdot} \mathrm{K}$ during cooling is in an agreement with the predicted ionic conductivity of phase II from proton dynamics $1.1 \cdot 10^{-4} \mathrm{~S} / \mathrm{m} \cdot \mathrm{K}$ [20]. In phase III at room temperature and $0.1 \mathrm{MPa}$ the measured conductivity of $\mathrm{CsHSO}_{4}$ is $2 \cdot 10^{-5} \mathrm{~S} / \mathrm{m} \cdot \mathrm{K}$ during heating cycle and $5 \cdot 10^{-7} \mathrm{~S} / \mathrm{m} \cdot \mathrm{K}$ during cooling cycle, which is within one order magnitude of the predicted conductivity $\sim 4 \cdot 10^{-6} \mathrm{~S} / \mathrm{m} \cdot \mathrm{K}$ at these conditions [20].

With the temperature increase from $300 \mathrm{~K}$ (phase III) to $\mathrm{T}_{\mathrm{c}}$ (phase I) the impedance spectra evolve from a perfect semi circle at high frequencies with $p \approx 0.90$ at room temperature to $p \approx 0.80$ at $405 \mathrm{~K}$ (Fig. 3). This parameter characterizes the deviation of dielectric relaxation function from a Debye type of relaxation.
According to [20] the spin-lattice relaxation of ${ }^{1} \mathrm{H}$ is non-exponential function with the stretched exponent which varies from 0.72 at $300 \mathrm{~K}$ to 0.64 at $410 \mathrm{~K}$. At $\mathrm{T}_{\mathrm{c}}$ the spectrum shape change drastically. Instead of the high frequency arc shoulder in Argand-diagrams the response appears as it would be from a pure active resistance (Fig. 2). The phase transition from phase II to phase I occurs in the temperature interval of about $\Delta \mathrm{T} \approx 5-6 \mathrm{~K}$. The question is what temperature should be chosen to identify $T_{c}$ ? In this study $T_{c}$ has been taken as a temperature at which the bulk impedance arc disappears from the impedance spectrum and the resistance of the equivalent electric circuit becomes almost active, $\mathrm{R}_{1}$ (Fig. 3). It reversibly occurs in a temperature range within $5-6 \mathrm{~K}$ during heating from phase II to phase I. At these temperatures $\tau$ becomes so small that it cannot be resolved at high frequencies (Fig. 2). For example, from the evolution of the impedance spectra at $\mathrm{P}=0.1$ $\mathrm{MPa}$ in Fig. 3, the phase transition from II to $\mathrm{I}$ is identified at $T_{c}=410.7 \pm 2.5 \mathrm{~K}$. At each pressure several consecutive heating-cooling cycles have been performed. The conductivity above $T_{c}$ is fully reproducible during heating and cooling cycles (Fig. 1). The absolute value of electrical conductivity measured in phase I at $434 \mathrm{~K}$ and $0.1 \mathrm{MPa}$ is 0.48 $\mathrm{S} / \mathrm{m}$, which is in a good agreement with previous measurements at room pressure $0.5 \mathrm{~S} / \mathrm{m}$ [21] and with the theoretically predicted value from the mean residence times determined from the spin-lattice relaxation times in phase $\mathrm{I} \sim 0.49 \mathrm{~S} / \mathrm{m}$ [22].

Contrary, the electrical conductivity measured at $\mathrm{T}<\mathrm{T}_{\mathrm{c}}$ demonstrates a significant hysteresis. The change of the slope at c. $340 \mathrm{~K}$ corresponds to the irreversible phase transition in the ferroelastic phase $P 2_{1 / c}$ [23]. In DSC measurements [10, 23] this transition has been identified as a transition from phase IV $\left(P 2_{1 / m}\right)$ into phase III, and the transition from phase III into phase II has been assigned to the temperature interval $363-380 \mathrm{~K}$. These two irreversible phase transitions have been observed only during heating, and during consecutive cooling the transitions are impeded due to the delay of spontaneous strain. After keeping the sample during several days at room temperature the low temperature transitions in ferroelastic phases appear again during heating cycles [23]. In the present experiments the transition at $340 \mathrm{~K}$ was observed also only during heating cycle. In earlier works with the use of 
constant frequency electrical conductivity measurements only one phase transition between IIIII phase during heating has been observed, which temperature at room pressure varied from $323 \mathrm{~K}$ [7] to $333 \mathrm{~K}$ [24]. Essentially, the behavior of electrical impedance in $\mathrm{CsHSO}_{4}$ under pressure in Fig. 1 during consecutive heating and cooling cycles is similar to what has been observed in $\mathrm{CsH}_{2} \mathrm{PO}_{4}$ [25] and in $\mathrm{KH}_{2} \mathrm{PO}_{4}$ and $\mathrm{RbH}_{2} \mathrm{PO}_{4}$ [26] at $1 \mathrm{GPa}$ in the solid medium transmitting medium high pressure apparatus.

Table 1 summarises the results of $T_{c}$ determination during heating and cooling cycles in the temperature range of the phase transition from the low conductivity phase II $\left(P 2_{l} / c\right)$ into the superionic high conductivity phase I $\left(14_{l} / a m d\right)$. Below $0.75 \mathrm{GPa}$ the electrical conductivity results presented in Fig. 1 and the determinations of $T_{c}$ as a function of pressure indicated in Table 1 are similar to the previous results of DSC [27] and electrical conductivity measurements $[4,11]$.

Table $1 \mathrm{~T}_{\mathrm{c}}$ measurements of phase transition in $\mathrm{CsHSO}_{4}$ from phase II to I at $\mathrm{P}<1 \mathrm{GPa}$ and IV-VI, VI-I at $\mathrm{P}>1 \mathrm{GPa}$

\begin{tabular}{|c|c|c|}
\hline Pressure, GPa & $\mathrm{T}_{\mathrm{c}}$ on heating, $\mathrm{K}$ & $\mathrm{T}_{\mathrm{c}}$ on cooling, $\mathrm{K}$ \\
\hline & II $\rightarrow$ I & $\mathrm{I}->$ II \\
\hline $0.1 \mathrm{MPa}$ & $410.7 \pm 2.5$ & $410.1 \pm 2.5$ \\
\hline 0.5 & $417.6 \pm 1.0$ & $412.0 \pm 2.5$ \\
\hline 0.75 & $419.6 \pm 3.0$ & n.d.* \\
\hline \multirow[t]{2}{*}{1.0} & $423.1 \pm 1.2$ & $418.9 \pm 3.0$ \\
\hline & IV->VI & VI- $>$ IV \\
\hline 1.5 & $453.6 \pm 1.7$ & $430.0 \pm 1.0$ \\
\hline 2.0 & $511.4 \pm 1.5$ & $482.0 \pm 4.5$ \\
\hline \multirow[t]{2}{*}{2.5} & $557.0 \pm 7.0$ & $536.0 \pm 3.5$ \\
\hline & VI->I & $\mathrm{I}->\mathrm{VI}$ \\
\hline 1.5 & $481.0 \pm 2.5$ & $475.0 \pm 4.0$ \\
\hline 2.0 & $532.0 \pm 4.0$ & $521.0 \pm 5.5$ \\
\hline 2.5 & $578.0 \pm 5.0$ & $565.0 \pm 6.0$ \\
\hline
\end{tabular}

*not determined.

With the help of the present electrical impedance method the phase transition between phases III and II is identified at around $340 \mathrm{~K}$ in the pressure range from $0.1 \mathrm{MPa}$ to $0.75 \mathrm{GPa}$, which is in disagreement with the value $330 \mathrm{~K}$ frequently reported in the literature $[7,10,11,27,28,29]$. The second low temperature phase transition at $375 \mathrm{~K}$ which was reported in [14, 23, 27] from DSC data, is not identified in the present study. Probably, the increase of electrical conductivity due to the increase of the exited state $\mathrm{H}\left(\mathrm{SO}_{4}\right)_{2}$ or $\mathrm{H}_{3}\left(\mathrm{SO}_{4}\right)_{2}$ at temperatures just below $\mathrm{T}_{\mathrm{c}}$ hiddens the change of $\ln (\sigma x T)$ slope in the Arrhenius curve (Fig. 1). There is only a small kink in the slope of $\ln (\sigma x T)$ vs. $1 / T, \mathrm{~K}$ (Fig. 1) in the temperature range close to $370 \mathrm{~K}$, but the exact position of this kink and the corresponding phase transition depends on the heating-cooling rate of a sample rather than on pressure. The DSC data measured at pressures $<0.12 \mathrm{GPa}$ from [14] demonstrated that the temperature of phase transition at $375 \mathrm{~K}-0.1 \mathrm{MPa}$ decreases with pressure and merges with the transition at $333 \mathrm{~K}-0.1 \mathrm{MPa}$. Thus, the $340 \mathrm{~K}$ transition observed in this study is identified as a phase III- phase II transition. A small increase of the activation energy of electrical conductivity at the temperature $300-400 \mathrm{~K}$ was observed only during the first heating of samples. The significant thermal hysteresis between heating and cooling cycles of the phase transition temperature in ferroelastic phases has been observed also in previous studies, and it was explained either as a surface phase transition [7] or as a kinetic phenomenon of spontaneous strain caused by the increase-decrease of domain size at $\mathrm{T}<\mathrm{T}_{\mathrm{c}}$ during cooling from high temperatures [23]. A significant discrepancy of the electrical conductivity (Fig. 1) and dielectric relaxation time (Fig. 2) during the heating and cooling cycles at $\mathrm{T}<\mathrm{T}_{\mathrm{c}}$ is obvious. The absolute values of the electrical conductivity and dielectric relaxation time vary significantly even at room temperature depending on how long the samples were kept at low temperatures. This sensitivity of electrical properties to the exposure time at room temperature can be due to a possible building of surface waterbearing phases enhancing the conduction of grain boundaries $[7,27]$ or due to the decrease of $\mathrm{H}\left(\mathrm{SO}_{4}\right)_{2}$ and $\mathrm{H}_{3}\left(\mathrm{SO}_{4}\right)_{2}$ exited states with time followed by the increase of domain size and the increase of spontaneous strain in ferroelastic phases [27]. Alternatively, it may be caused by the change in a reduction degree of $\mathrm{CsHSO}_{4}$ with the increasing moisture content, which activates acid centres on grain boundaries [30]. 
Figs. 4, 5, 6 and 7 summarize the results of electrical conductivity and dielectric relaxation time measurements obtained during two consecutive heating -cooling cycles at $1,1.5,2$, and $2.5 \mathrm{GPa}$ respectively. At high pressures and at $\mathrm{T}<\mathrm{T}_{\mathrm{c}}$ the kinks in slopes of $\ln (\sigma x T)$ and $\ln (\tau)$ as function of $1 / T, K$ which can be interpreted as phase transition boundaries, are observed only during heating cycle. This means that the pressure increase delays the effect of spontaneous strain in ferroelastic phases under cooling. During cooling the phase which appears below $T_{c}$ is stable up to $300 \mathrm{~K}$. Only after $1-2$ day of keeping the sample at room temperature the electrical conductivity returns slowly to the values, which were measured before the last heating-cooling cycle conforming to the results of [23] obtained at 0.1 $\mathrm{MPa}$.

3 Discussion The calculated slopes or the activation energies of the bulk electrical conductivity $\sigma x T\left(E_{\sigma}\right)$ and dielectric relaxation time $\tau\left(E_{\tau}\right)$ at $\mathrm{P}<1$ $\mathrm{GPa}$ are summarized in Table 2 and at $\mathrm{P}>1 \mathrm{GPa}$ in Table 3. The activation energy of $E_{\sigma}$ or $E_{\tau}$ may be used as an indirect marker of phases to be identified from the electrical impedance measurements.

In the present study the slope of phase boundaries IV-VI and VI-I is about $100-105 \mathrm{~K} / \mathrm{GPa}$ in comparison with $63-65 \mathrm{~K} / \mathrm{GPa}$ reported in [4]. From the electrical conductivity data it is not possible to identify the location of phase boundary of the intermediate superionic phase VII during the heating cycle (Figs. 6-7). The heating and cooling paths are very different at $\mathrm{P}>1 \mathrm{GPa}$ in contrast to the measurements at $\mathrm{P}<1 \mathrm{GPa}$. At high temperatures $\mathrm{T}$ $>\mathrm{T}_{\mathrm{c}}$ the activation energy is $\mathrm{E}_{\sigma} \sim 0.37 \pm 0.05 \mathrm{eV}$ at $\mathrm{P}<$ $1 \mathrm{GPa}$ and $\mathrm{E}_{\sigma} \approx 0.30 \pm 0.05 \mathrm{eV}$ at $\mathrm{P}>1 \mathrm{GPa}$. This value of $E_{\sigma}$ at $T>T_{c}$ is practically independent on pressure. For phase II the activation energy is c. 0.52 $\mathrm{eV}$ and for phase III $0.70 \mathrm{eV}$ (Table 2). From other side, the ${ }^{1} \mathrm{H}$ MAS NMR data [11] demonstrated about the same activation energy for the proton mean residence time $\sim 0.36 \mathrm{eV}$ in superprotonic phase at room pressure and twice less activation energy 0.26 $\mathrm{eV}$ in ferroelastic phase $\mathrm{CsHSO}_{4}$ (II). In [19] these results have been reproduced, the values $0.35 \mathrm{eV}$ and $0.3 \mathrm{eV}$ for superprotonic and phase II were reported, respectively. This means that in superprotonic phase I the density of mobile protons is fixed and does not depend on pressure and temperature, $N=8.48 \cdot 10^{27} \mathrm{~m}^{-}$ 3 which was calculated from the crystal structure
[19]. Thus, the super ionic phase I is a typical protonic conductor, which appears above $\mathrm{T}_{\mathrm{c}}$. The measured values of the activation energy $E_{\sigma}$ are slightly higher than the previously reported values of the activation energy of electrical conductivity 0.31 $\mathrm{eV}$ [11], $0.28 \mathrm{eV}$ [21] and $0.27 \mathrm{eV}$ [31]. The phase II $\left(P 2_{l} / c\right)$ which exists below $330 \mathrm{~K}$ and at pressures below $1 \mathrm{GPa}, \mathrm{E}_{\sigma} \sim 0.75-0.60 \mathrm{eV}$, which is in agreement with the reported values $\mathrm{E}_{\sigma} \sim 0.76-0.79 \mathrm{eV}$ according to [31]. This value is twice higher than the activation energy of the mean residence time of protons or the mobility activation energy $\sim 0.3 \mathrm{eV}$, which means that the number of mobile protons varies with temperature below $T_{c}$, and the activation energy of this process is about $0.3-0.45 \mathrm{eV}$. In phase $\operatorname{IV}\left(P{ }_{1} / m\right)$ the activation energy is about $\mathrm{E}_{\sigma} \sim 0.6-0.5$ $\mathrm{eV}$, close to the values of the phase II.

The identification of the phase boundaries between low conductivity phases with the use of electrical conductivity measurements is not so straight forward. Due to the small differences in slopes of $\ln (\sigma x T)$ and $\ln (\tau)$ as a function of $1 / T, K$, these phases have a negligible difference of activation energies (Table 2). The phase IV or the second phase transition in ferroelastic phases as it sometimes mentioned in the literature [23], was not observed under pressure $<1 \mathrm{GPa}$ which is in agreement with the results of [14]. The significant decrease of the phase transition temperature from phase III into phase II at low pressures $(<0.1 \mathrm{GPa})$ mentioned in [14] is not supported by the present measurements (Fig. 1).

The electrical conductivity mechanism in phase I, II, and III has been discussed in $[6,11,32,33]$. The high conductivity and the relatively low activation energy of the fast ionic conductor phase I is provided by two simultaneously acting processes, the reorientation of $\mathrm{HSO}_{4}$ groups having the activation energy c. $0.35 \mathrm{eV}$, and the long range translation diffusion of protons along hydrogen bonds having the activation energy $0.25 \mathrm{eV}[11,23,33]$. In phase III the hydrogen bonds are stronger than in phase II, the lattice is rigid. With the temperature increase the spin-lattice relaxation time decreases and the spin-spin relaxation time increases. During the inversion from phase III into phase II the transition temperature corresponds to an abrupt decrease and an increase of longitudinal and transversal decay constants of NMR [32]. The relaxation of the rotating frame decay constant has a minimum at $375 \mathrm{~K}$. Thus, $375 \mathrm{~K}$ phase transition may be considered as a kinetic pseudo glass transition 
which is effectively suppressed under pressure. In superprotonic phase I reorientational and translational decay constant are equal, the temperature increase results in averaging of the anisotropic interactions of $\mathrm{HSO}_{4}{ }^{-}$ions. The activation energy of electrical conductivity along the crystallographic axes $b$ and $c$ in phase II $\left(P 2_{l} / c\right)$ phase are 0.73 and $0.97 \mathrm{eV}$ in comparison with 0.25 and $0.28 \mathrm{eV}$ in the phase I $\left(\mathrm{I}_{1} /\right.$ amd $)$ [34]. Thus, with the temperature increase the number of mobile protons increases gradually at $\mathrm{T}>330 \mathrm{~K}$ and reaches a constant value in phase II [6]. In phase I at $\mathrm{T}>\mathrm{T}_{\mathrm{c}}$ the number of mobile protons which could hop from one hydrogen bond to another remains constant but their mobility increases drastically due to the activated reorientation movement of $\mathrm{SO}_{4}{ }^{2-}$ tetrahedra. From the present high pressure measurements of electrical conductivity it seems that the pressure does not have any effect on this process. The increased disordering of $\mathrm{SO}_{4}{ }^{2-}$ tertrahedra with the temperature increase plays a crucial role in the enhanced conductivity of phase I, the thermal disordering of protons itself is of minor importance [33].

Table 2 Activation energies from IS measurements at $\mathrm{P}<1 \mathrm{GPa}$.

\begin{tabular}{|c|c|c|c|}
\hline Pressure, GPa & $\mathrm{T}<\mathrm{T}^{1}$ & $\mathrm{~T}^{1}<\mathrm{T}<\mathrm{T}_{\mathrm{c}}$ & $\mathrm{T}>\mathrm{T}_{\mathrm{c}}$ \\
\hline $0.1 \mathrm{MPa}$ & & & \\
\hline $\begin{array}{l}\left(\mathrm{T}^{1}=\mathrm{T}_{\mathrm{II}^{-} \mathrm{II}} \sim 340 \mathrm{~K}\right) \\
\mathbf{0 . 5}\end{array}$ & $0.75^{*} / 0.7^{*}$ & $* 0.57 * / 0.52 * *$ & $0.37 *$ \\
\hline$\left(\mathrm{T}^{1}=\mathrm{T}_{\mathrm{II}^{-} \mathrm{III}} \sim 340 \mathrm{~K}\right)$ & $0.73 / 0.72$ & $0.58 / 0.54$ & 0.36 \\
\hline $\begin{array}{l}\mathbf{0 . 7 5} \\
\left(\mathrm{T}^{1}=\mathrm{T}_{\mathrm{II}^{-}} \mathrm{III} \sim 340 \mathrm{~K}\right)\end{array}$ & $0.62 / 0.60$ & $0.58 / 0.60$ & 0.37 \\
\hline $\begin{array}{l}\mathbf{1 . 0} \\
\left(\mathrm{T}^{1}=\mathrm{T}_{\mathrm{II}}{ }_{\mathrm{IV}} \sim 370 \mathrm{~K}\right)\end{array}$ & $0.40 / 0.38$ & $0.50 / 0.45$ & 0.33 \\
\hline
\end{tabular}

* $\mathrm{E}_{\sigma}$ of $\sigma_{D C} \mathrm{x} T$ bulk conductivity in $\mathrm{eV}$ calculated from $\mathrm{Eq}$ 2.

** $\mathrm{E}_{\tau}$ of $\tau$ in eV dielectric relaxation time from $\mathrm{Eq} 3$.

Nevertheless, if one judges from the results of activation energy of electrical conductivity and dielectric relaxation time at $1 \mathrm{GPa}$ the phase which exists at $\mathrm{T}<370 \mathrm{~K}$ is different from phase III occurring at lower pressures. According to the classification of $[7,28,29,34,35]$ this is probably phase $\operatorname{IV}\left(P 2_{l} / m\right)$, possessing the activation energy $E_{\sigma}$ c. $0.4 \mathrm{eV}$. The same phase is observed at $1.5 \mathrm{GPa}$ at $375 \mathrm{~K}<\mathrm{T}<$ $454 \mathrm{~K}$ and at $2.0 \mathrm{GPa}$ at $445 \mathrm{~K}<\mathrm{T}<515 \mathrm{~K}$. Phase III at $\mathrm{P}=1 \mathrm{GPa}$ was not observed at low temperatures $\mathrm{T}<$ $330 \mathrm{~K}$. In $[23,35]$ the irreversible transformation of phase II into III (or IV) at 0.75-1.1 GPa has been explained due to the pressure stabilization effect of the phase II structure. At $1.25 \mathrm{GPa}$ phase II transforms into phase IV [36]. Under cooling the domain size of phase II, which is transformed from phase I, is small, and this causes a kinetic delay of the phase II into low temperature phase. During annealing over 2-3 days at low temperatures $\mathrm{T} \sim 300 \mathrm{~K}$ and at high pressures $\mathrm{P}=0.5-1 \mathrm{GPa}$, the ferroelastic phases III and IV have been observed again judging from the activation energy of the electrical conductivity $\mathrm{E}_{\sigma}$ during second heating cycle (Figs. 1 and 4).

Phase $\mathrm{V}$ observed at room temperature at $\mathrm{P}>1.4 \mathrm{GPa}$ is monoclinic $P 2_{1} / m$ or $P 2_{1}$ [36], and in the present experiments appeared at $1.5 \mathrm{GPa}$ having the activation energy of electrical conductivity $\mathrm{E}_{\sigma} \sim 0.63$ $\mathrm{eV}$. Phase VI is the intermediate superprotonic phase with Pnma symmetry [36] has been observed in this study at $\mathrm{P}>1.5 \mathrm{GPa}$ possessing the activation energy of electrical conductivity $\mathrm{E}_{\sigma} \sim 1.4 \mathrm{eV}$ (Table 3 )

Table 3 Activation energies from IS measurements at $\mathrm{P}>1 \mathrm{GPa}$.

\begin{tabular}{lllll}
\hline Pressure, GPa & $\mathrm{T}<\mathrm{T}_{1}$ & $\mathrm{~T}^{1}<\mathrm{T}<\mathrm{T}^{2}$ & $\mathrm{~T}^{2}<\mathrm{T}<\mathrm{T}_{\mathrm{c}}$ & $\mathrm{T}>\mathrm{T}_{\mathrm{c}}$ \\
\hline $\mathbf{1 . 5}$ & $0.63 / 0.65$ & $0.31 / 0.33$ & 1.40 & 0.32 \\
$\left(\mathrm{~T}^{1}=\mathrm{T}_{\mathrm{V}^{-} \mathrm{IV}} \sim 375 \mathrm{~K}\right.$, & & & \\
$\left.\mathrm{T}^{2}=\mathrm{T}_{\mathrm{IV}}-\mathrm{VI} \sim 454 \mathrm{~K}\right)$ & & & \\
$\mathbf{2 . 0}$ & $0.55 / 0.56$ & $0.40 / 0.38$ & 1.35 & 0.30 \\
$\left(\mathrm{~T}^{1}=\mathrm{T}_{\mathrm{V}-\mathrm{IV}} \sim 445 \mathrm{~K}\right.$, & & & \\
$\left.\mathrm{T}^{2}=\mathrm{T}_{\mathrm{IV}-\mathrm{VI}} \sim 515 \mathrm{~K}\right)$ & & & \\
$\mathbf{2 . 5}$ & $0.50 / 0.49$ & $0.31 / 0.29$ & 1.70 & 0.31 \\
$\left(\mathrm{~T}^{1}=\mathrm{T}_{\mathrm{VIII}}\right.$ & & & \\
$\mathrm{V}^{\sim 350 \mathrm{~K},}$ & $\mathrm{~T}^{2 *}<\mathrm{T}<\mathrm{T}^{3}$ & & \\
$\mathrm{~T}^{2 *}=\mathrm{T}_{\mathrm{V}-\mathrm{IV}} \sim 460 \mathrm{~K}$, & $0.65 / 0.60$ & \\
$\left.\mathrm{~T}^{3}=\mathrm{T}_{\mathrm{V}-\mathrm{IV}} \sim 505 \mathrm{~K}\right)$ & & & \\
\hline
\end{tabular}

At $2.5 \mathrm{GPa}$ the phase which exists at room temperature is different from that at $2.0 \mathrm{GPa}$. This probably corresponds to phase VIII, which existence has been suggested in [29]. The phase transforms into phase $\mathrm{V}$ at $350 \mathrm{~K}$. At pressures 1.5-2.5 GPa the jump of electrical conductivity from the low conductive ferroelastic phases into the fast protonic conductor phase occurs in two steps (Figs. 5-7), which has been observed also in previous studies [4, 7]. At $2.5 \mathrm{GPa}$ during cooling between phases I and VI there is a temperature interval $570 \mathrm{~K}<\mathrm{T}<585 \mathrm{~K}$ where the activation energy is $\mathrm{E}_{\sigma} \sim 0.8-1.0 \mathrm{eV}$ (Fig. 7). This can be interpreted as an occurrence of the intermediate fast ionic conductor phase VII, but even upon heating 
the jump of electrical conductivity is negligible, so this phase was practically undistinguishable.

The phase transition boundaries between low conductivity phase II and super ionic phase I at $\mathrm{P}<1$ $\mathrm{GPa}$ identified from electrical conductivity measurements are indicated in Table 1 and summarized in Fig. 8 (upper panel). The Clapeyron slope of the phase boundary between phases II and I at low pressures $d T_{c} / d P \sim 10 \mathrm{~K} / \mathrm{GPa}$ which is in a good agreement with previous studies [4, 9, 25]. Thus, the phase boundaries of $\mathrm{CsHSO}_{4}$ at $\mathrm{P}<1 \mathrm{GPa}$ are not very much different from previous results (Fig. 8, upper panel). The main difference of the results of this study from previous measurements [4] is in the location of phase transition boundaries at $\mathrm{P}>$ $1 \mathrm{GPa}$ (Fig. 8 upper panel). According to [4], in which the electrical measurements were carried out at a fixed $1 \mathrm{kHz}$ frequency, the phase transition II-I splits with the appearance of the second intermediate high conductive phase VI. The slopes of the both transitions IV-VI and VI-I were determined in [4] is about $65 \mathrm{~K} / \mathrm{GPa}$. In this study this phase boundary slope is $\sim 100 \mathrm{~K} / \mathrm{GPa}$. At pressure about $1.8 \mathrm{GPa}$ another intermediate super ionic phase VII was reported in [4], which appears between the phase boundaries of phases VI and I. There is no firm confirmation of the existence of phase VII from this study, and this phase may occur at higher temperatures and pressures.

The phase boundaries between the low conductive phases are poorly determined in this study. In the lower panel of Fig. 8 the temperatures which correspond to the probable phase transitions are plotted as a tentative phase diagram. The interpretations of kinks in slopes of $\ln (\sigma x T)$ vs. $1 / T$ were made on the basis of the previous experimental phase diagram [4]. The indicated phase boundaries are more conforming to recent experimental results of $[10,36,37]$ rather than to results of [4]. Phase IV is stable at $1.25 \mathrm{GPa}$ and room temperature [36], phase II is stable in the range $0.75-1.1 \mathrm{GPa}$ [37]. It should be noted here that in situ determinations of phases are highly needed for the interpretation of electrical conductivity measurements at high pressure..

4 Conclusions The IS measurements on polycrystalline $\mathrm{CsHSO}_{4}$ at pressure up to $2.5 \mathrm{GPa}$ have confirmed the location of the phase boundary III at $\mathrm{P}<1 \mathrm{GPa}$. This study also demonstrated that the high pressure phase boundaries at $\mathrm{P}>1 \mathrm{GPa}$ are different from the previous results [4].

1. The reversible phase transition from phase II into phase $\mathrm{I}$ is observed at pressures from 0.1 $\mathrm{MPa}$ to $0.75 \mathrm{GPa}$ with the Clapeyron slope $d T_{c} / d P \sim 10 \mathrm{~K} / \mathrm{GPa}$. The activation energy of the electric conductivity and dielectric relaxation time in phase $\mathrm{I}$ is c. $0.35 \mathrm{eV}$ and which is equal to the mean residence time of protons. This value seems to be independent on pressure.

2. The Clapeyron slope of the reversible phase transition from the super ionic phase VI into phase $\mathrm{I}$ at $\mathrm{P}>1 \mathrm{GPa}$ is $\sim 100 \mathrm{~K} / \mathrm{GPa}$.

3. The intermediate fast ionic conductor phase VI possesses the activation energy $E_{s} \sim 1.4 \mathrm{eV}$ and the Clapeyron slope of the transformation of phase VI into phase IV is also $\sim 100 \mathrm{~K} / \mathrm{GPa}$.

4. The phase VII which has the activation energy $E_{s} \sim 0.8-1.0 \mathrm{eV}$ appears only during cooling from phase I.

5. At $2.5 \mathrm{GPa}$ below $350 \mathrm{~K}$ phase VIII is observed with the activation energy of electrical conductivity c. $0.5 \mathrm{eV}$.

Acknowledgements The author is thankful to M. Lutschitzkaya for the synthesis of $\mathrm{CsHSO}_{4}$ samples.

\section{References}

[1] K.-D. Kreuer, Chem Mater 8, 610 (1996).

[2] S. M. Haile, Acta Materialia 51, 5981 (2003).

[3] M. Komukae, T. Osaka, Y. Makita, T. Ozaki, K. Itoh, and E. Nakamura, Journ Phys Soc Jap 50, 3187 (1981).

[4] E. G. Ponyatovskiĩ, V. I Rashchupkin, V. V. Sinitsyn, A. I. Baranov, L. A. Shuvalov, and N. M. Shchagina, JETP Lett 41, 139 (1985).

[5] M. Pham-Thi, Ph. Colomban, A. Novak, and R. Blinc, Solid State Comm 55, 265 (1985).

[6] Y. Yoshida, Y. Matsuo, and S. Ikehata, Journ Phys Soc Jap 72, 1590 (2003).

[7] A. I. Baranov, V. V. Sinitsyn, E. G. Ponyatovskiĩ, and L. A. Shuvalov, JETP Lett 44, 237 (1986).

[8] E. Ortiz, R. A. Vargas, and B.-E. Mellander, J Phys: Condens Matter 18, 9561 (2006). 
[9] B. Baranowski, J. Lipkowski, and A. Lundén, Journ Solid State Chem 117, 412 (1995).

[10] A. Lundén, B. Baranowski, and M. Friesel, Ferroelectrics 167, 33 (1995).

[11] V. V. Sinitsyn, A. I. Privalov, O. Lips, A. I. Baranov, D. Kruk, and F. Fujara, Ionics 14, 223 (2008).

[12] D. A. Boysen, C. R. I. Chisholm, S. M. Haile, and S. R. Narayanan, Journ Electrochem Soc 147, 3610 (2000).

[13] V. G. Ponomareva and G. V. Lavrova, Solid State Ionics 145, 197 (2001).

[14] B. Baranowski, M Friesel, and A. Lundén, Physica A 156, 353 (1989).

[15] C. Chisholm and S. M. Haile, Chem Mater 19, 270 (2007).

[16] N. Bagdassarov, C.-H. Freiheit, and A. Putnis, Solid State Ionics, 143, 285 (2001).

[17] A. K. Jonscher, Journ Phys D: Appl Phys 32, R57 (1999).

[18] D. L. Sidebottom, P. F. Green, and R. K. Brow, Phys Rev Letters 74, 5068 (1995).

[19] Y. Daiko, S. Hayashi, and A. Matsuda, Chem Mater 22, 3418 (2010).

[20] M. Mizuno and S. Hayashi, Solid State Ionics 167, 317 (2004).

[21] T. Norby, M. Friesel, and B. E. Mellander, Solid State Ionics 77, 105 (1995).

[22] S. Hayashi, and M. Mizuno, Solid State Ionics 171, 289 (2004).

[23] T. Kato, J. Hatori, Y. Yoshida, Y. Matsuo, and S. Ikehata, Solid State Ionics 178, 735 (2007).

[24] A. I. Baranov, L. A. Shuvalov, and N. M. Shchagina, JETPh Letts 36(11), 381 (1982).

[25] D. A. Boysen, S. Haile, H. Liu, and R. A. Secco, Chem Mater 15, 727 (2003).

[26] D. A. Boysen, S. Haile, H. Liu, and R. A. Secco, Chem Mater 16, 693 (2004).

[27] M. Friesel, B. Baranowski, and A. Lundén, Solid State Ionics 35, 85 (1989).

[28] N.M. Plakida and V. S. Shakhmatov, Ferroelectrics 167, 73 (1995).

[29] V. S. Shakhmatov, High Pressure Res 14, 67 (1995).

[30] V. G. Ponomareva, and G. V. Lavrova, Inorganic Materials 45, 85 (2009).

[31] H. K. Shin, Solid State Ionics 179, 2101 (2008).
[32] A. Damyanovich, M. M. Pintar, R. Blinc, and J. Slak, Physical Rev B 56, 7942 (1997).

[33] S. Hayashi, and M. Mizuno, Solid State Comm 132, 443 (2004).

[34] A. I. Baranov, B. V. Merinov, A. V. Tregubchenko, V. P. Khiznichenko, L. A. Shuvalov, and N. M. Schagina, Solid State Ionics 36, 279 (1989).

[35] A. V. Belushkin, M. A. Adams, S. Hull, A. I. Kolesnikov, and L. A. Shuvalov, Physica B 213\&214, 1034 (1995).

[36] A. V. Belushkin, M. A. Adams, S. Hull, and L. A. Shuvalov, Solid State Ionics 77, 91 (1995).

[37] A. V. Belushkin, T. Mhiri, and S. F. Parker, Physica B 234-236, 92 (1997). 

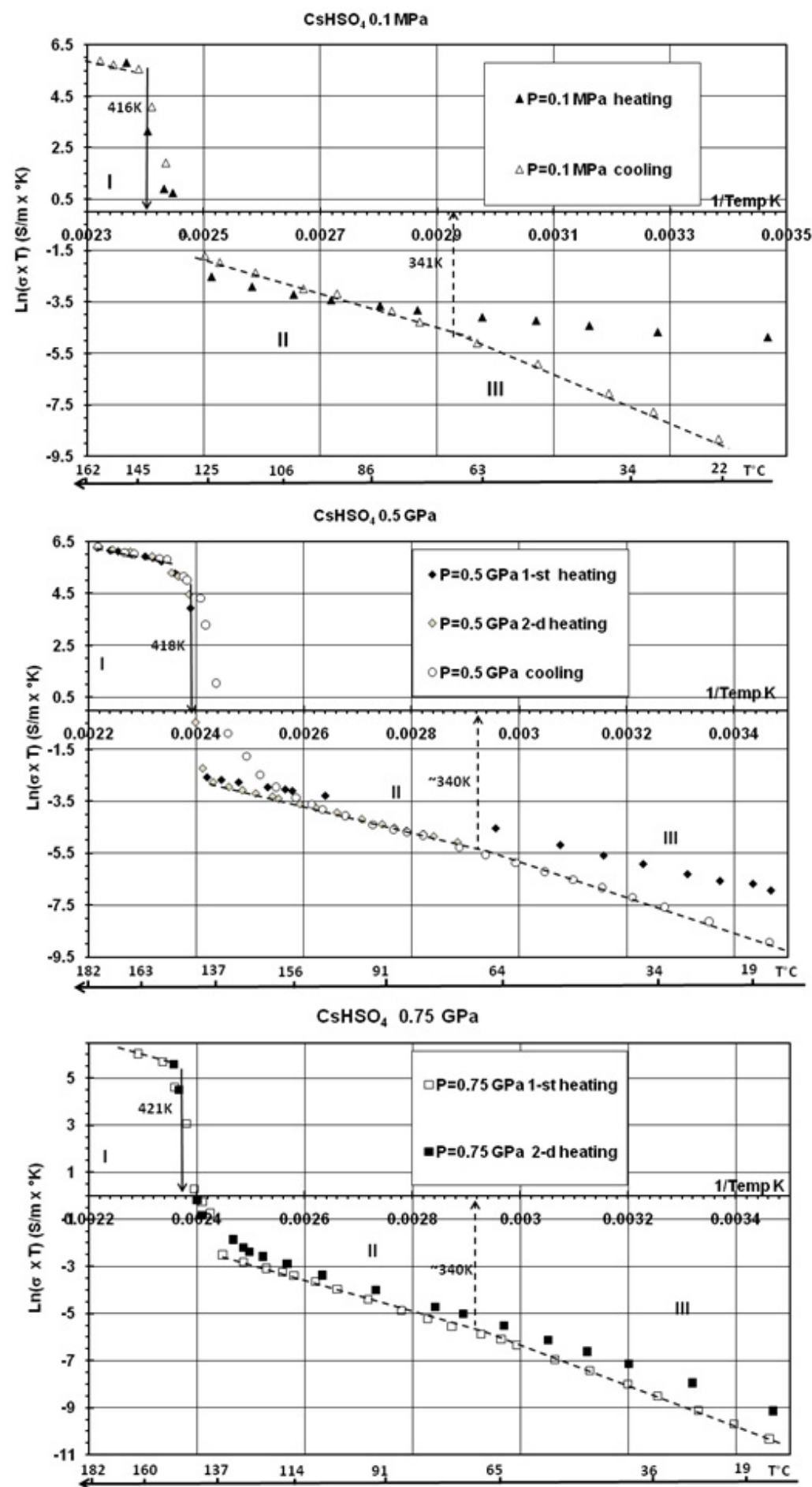

Figure 1 Electric conductivity in $\mathrm{CsHSO}_{4}$ at $0.1 \mathrm{MPa}, 0.5$ and $0.75 \mathrm{GPa}$. 


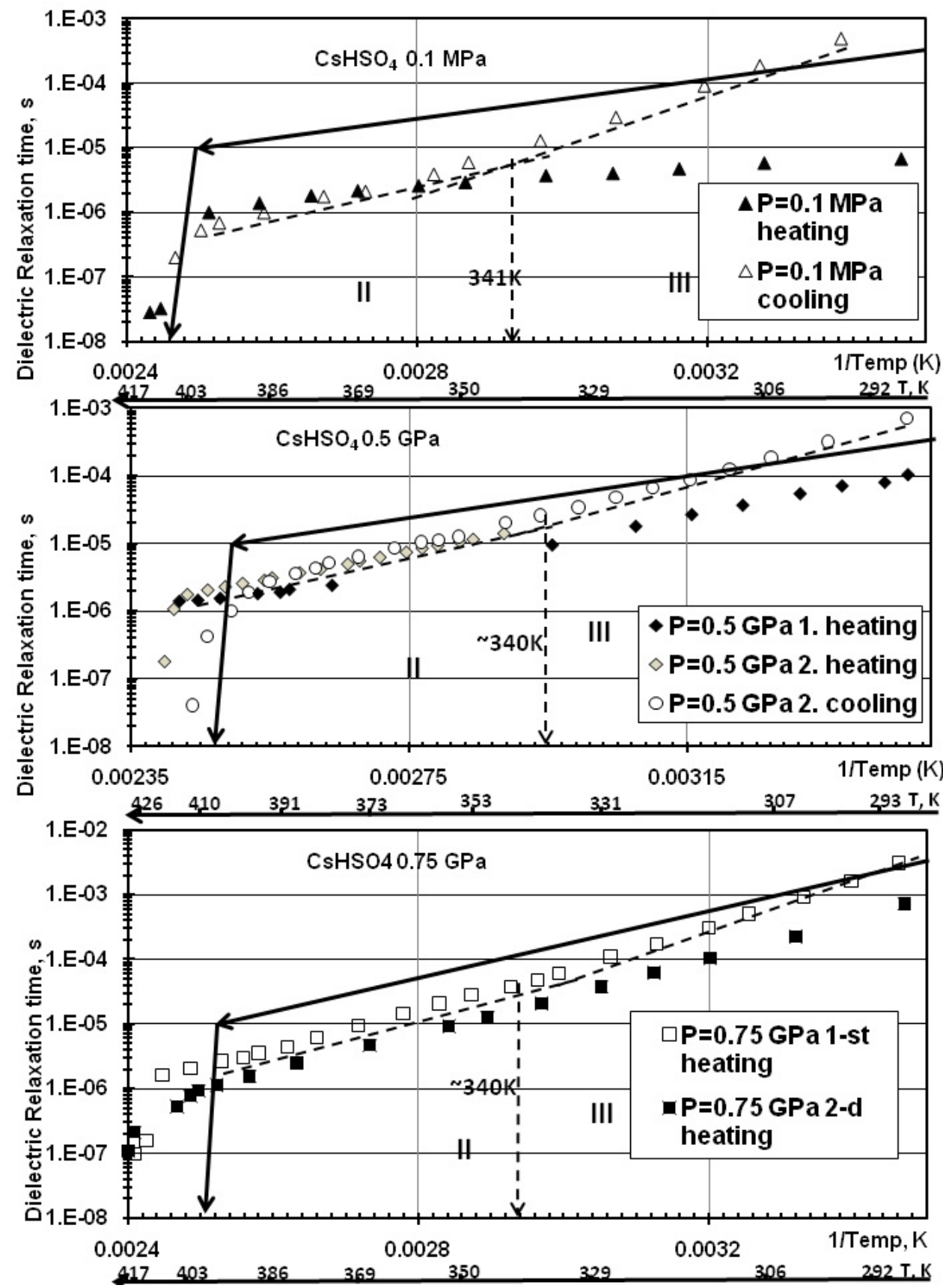

Figure 2 Dielectric relaxation time in $\mathrm{CsHSO}_{4}$ at 0.1

$\mathrm{MPa}, 0.5$ and $0.75 \mathrm{GPa}$. Solid arrows indicate the

drop of the mean residence time $\tau_{H}$ of spin-lattice relaxation [19]. 

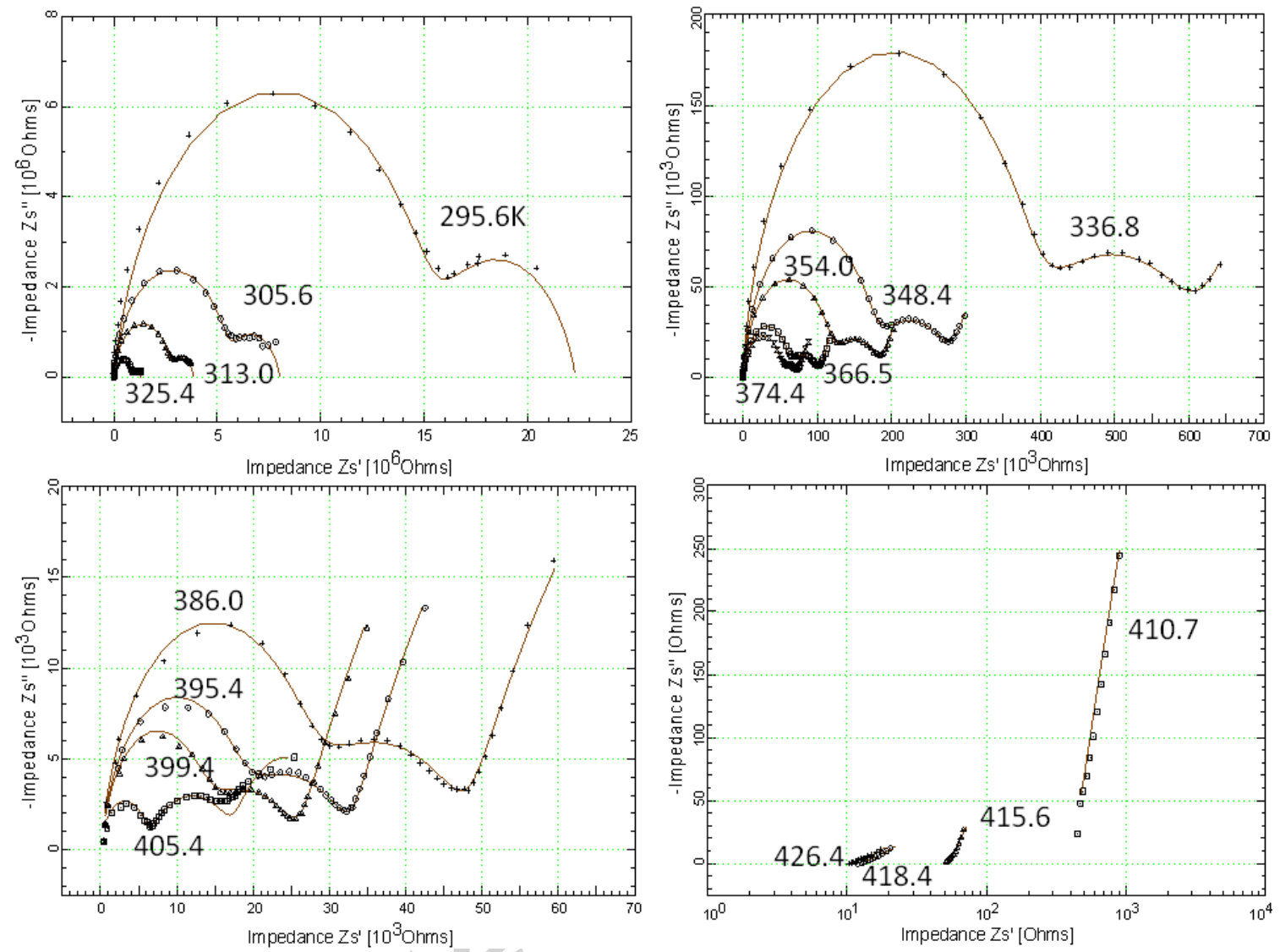

Figure 3 Evolution of impedance spectra at $\mathrm{P}=0.1 \mathrm{MPa}$.

The Phase transition II $=>$ I corresponds to the abrupt change of impedance spectra (right lower panel). The left arc in the Argand plots is the bulk impedance; the small intermediate arc is probably the grain boundary phase impedance. The right shoulder of the spectra is Wagner impedance branch. The parameter $p$ from Eq 1 varies from 0.89 at $295.6 \mathrm{~K}$ to 0.80 at $405.4 \mathrm{~K}$. 

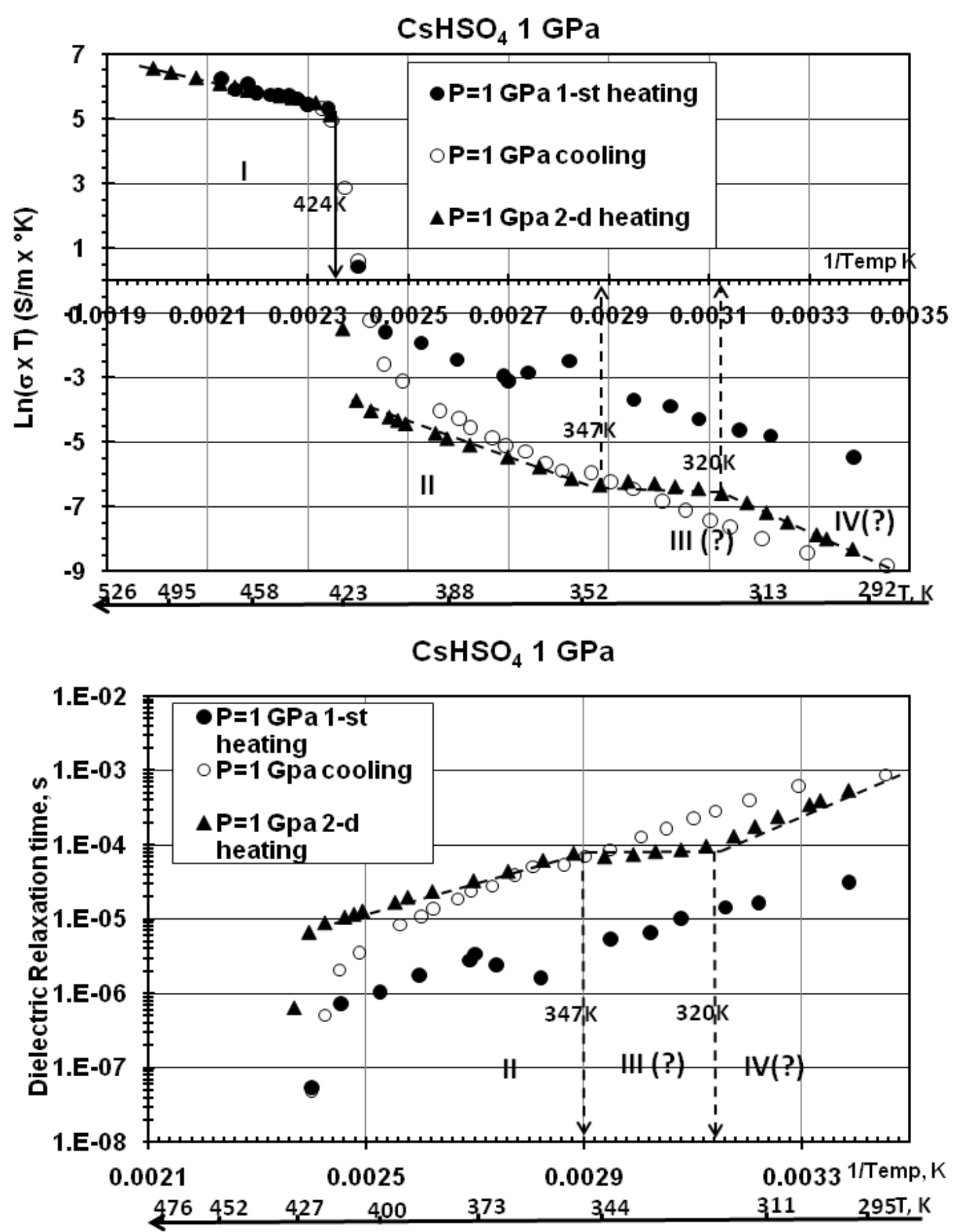

Figure 4 Electrical conductivity $\sigma$ and dielectric relaxation time $\tau$ at $1 \mathrm{GPa}$ : phase I is superprotonic, phases II-IV are 

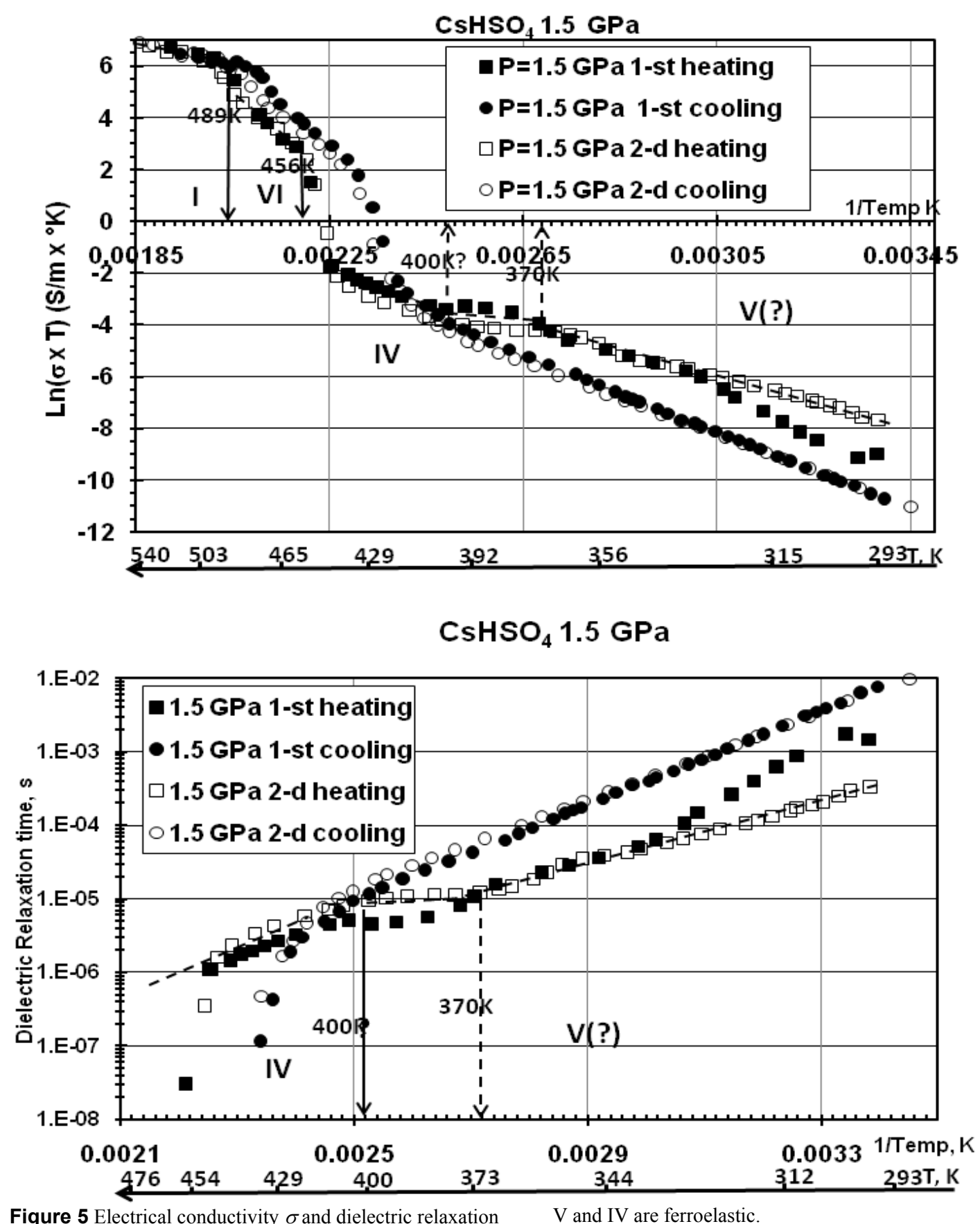

Figure 5 Electrical conductivity $\sigma$ and dielectric relaxation time $\tau$ at $1.5 \mathrm{GPa}$ : phase I and VI are superprotonic, phases 

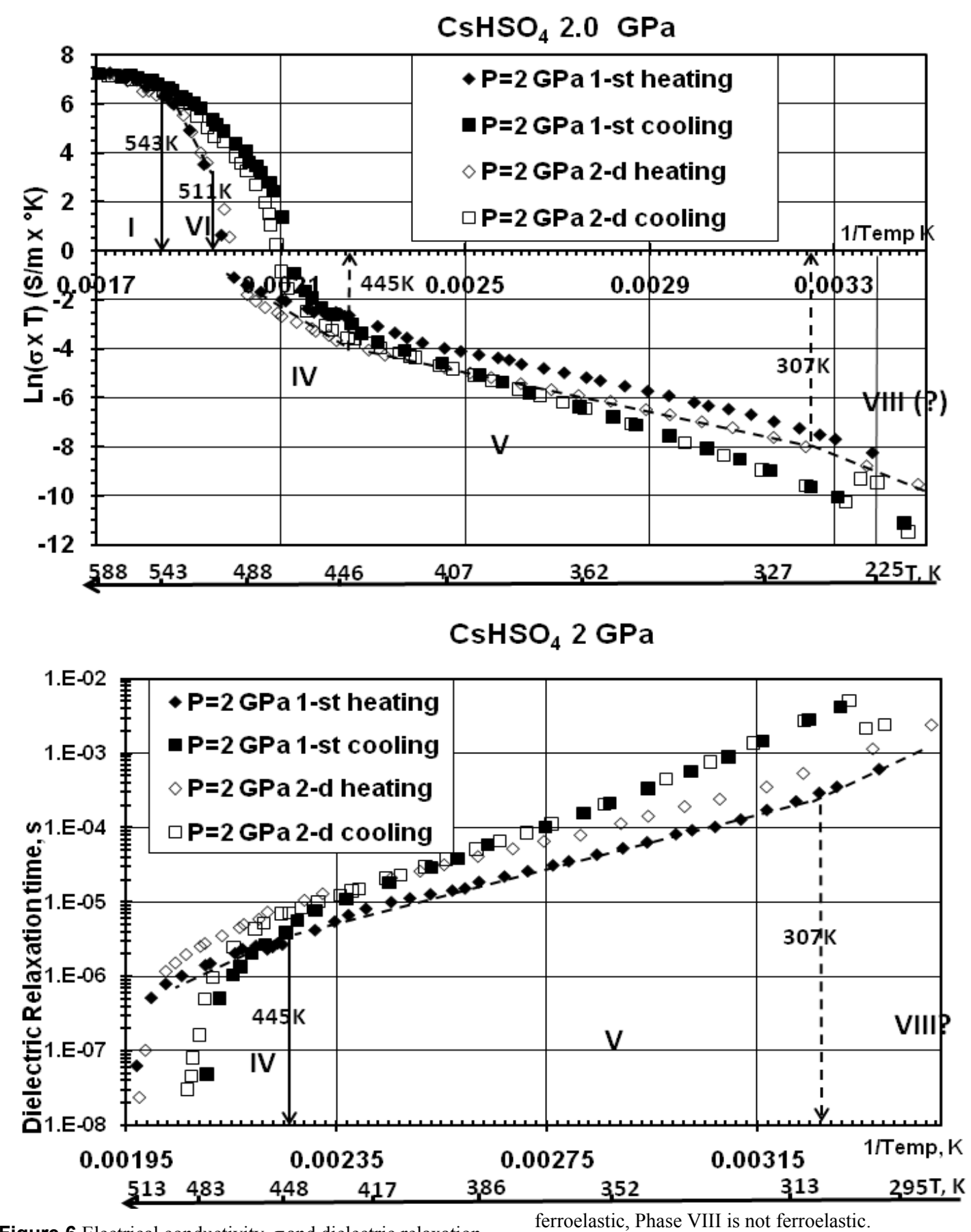

Figure 6 Electrical conductivity $\sigma$ and dielectric relaxation time $\tau$ at $2 \mathrm{GPa}$ : phases I and VI are superprotonic, phase V 

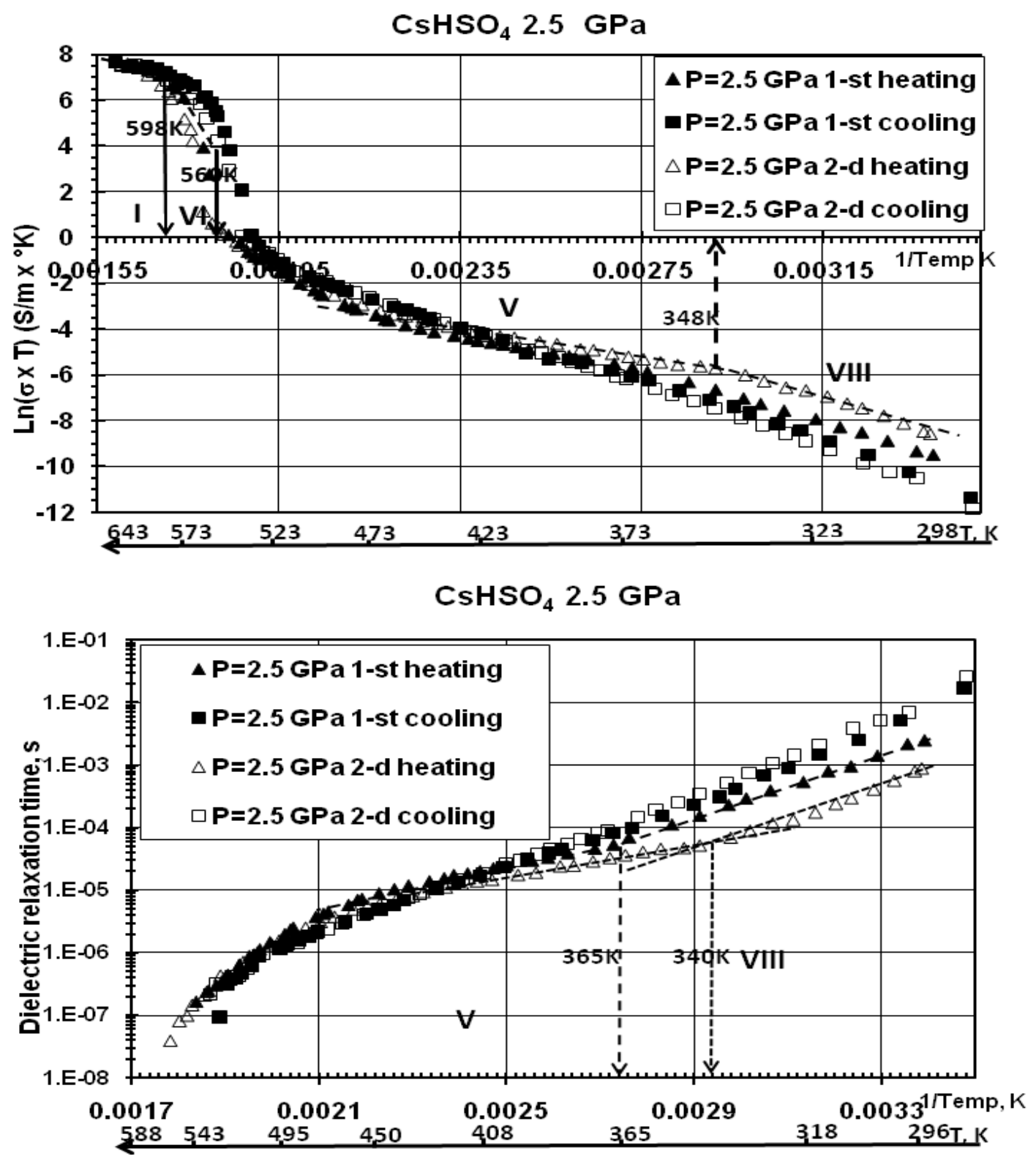
Figure 7 Electrical conductivity $\sigma$ and dielectric relaxation time $\tau$ at $2.5 \mathrm{GPa}$, phases $\mathrm{V}$ and VIII are probablynot ferroelastic, small knick in slope is observed during cooling cycle.
Figure 8 Phase diagram derived from electrical impedance measurements in comparison with previous data [4, 9]: upper panel represents phase transitions in superprotonic phases; lower panel represents a tentative diagram of phase transitions in ferroelastic phases based on electrical impedance measurements of this study.

Research Highlights:
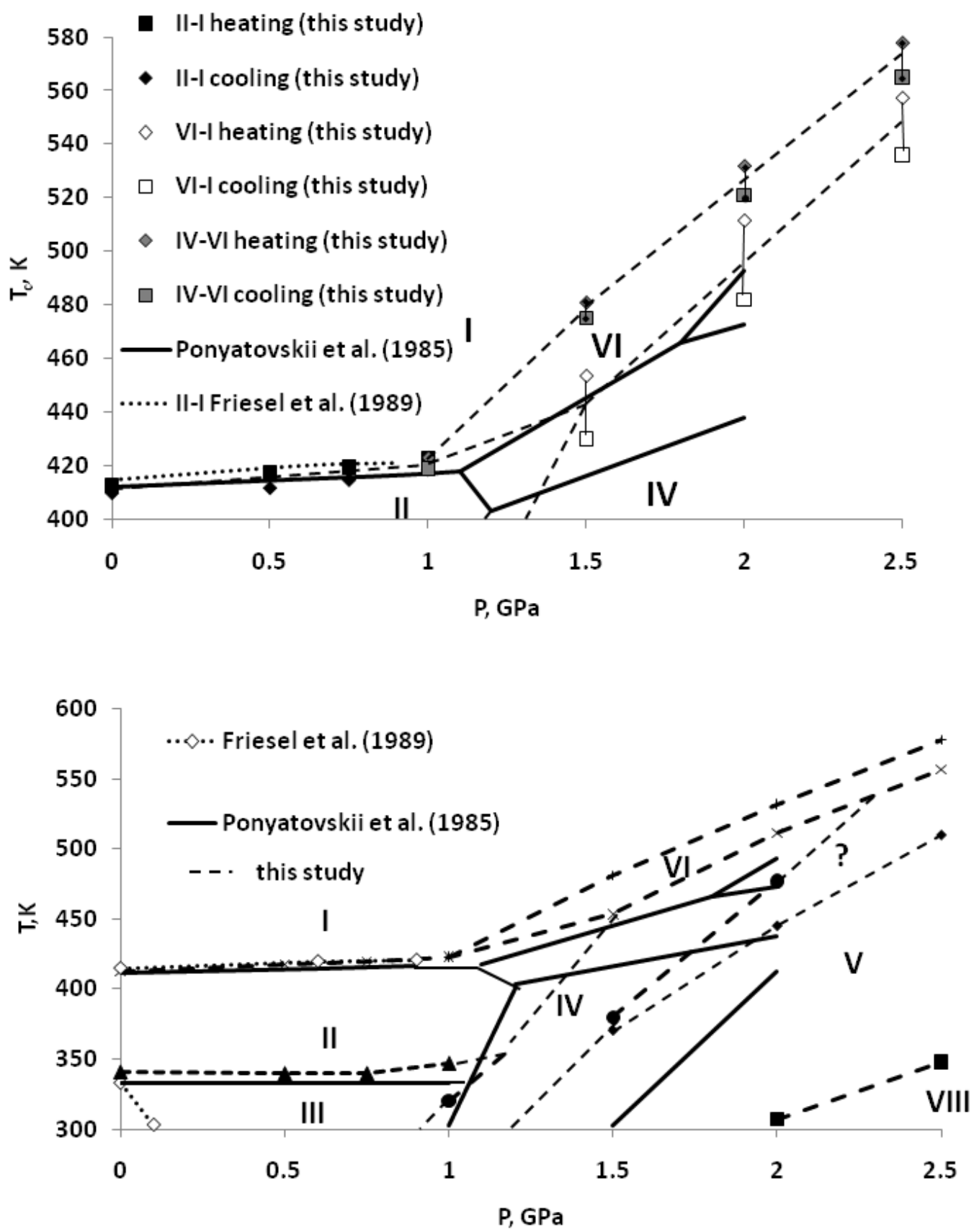
Phase transitions in $\mathrm{CsHSO}_{4}$ at pressures from $0.1 \mathrm{MPa}$ to $2.5 \mathrm{GPa}$ have been studied with the help of electrical impedance measurements. The phase boundaries have been identified with the help of calculated activation energies of electrical conductivity and dielectric relaxation time. The phase boundary between protonic superconducting and ferrolastic phases corresponds to the Clapeyron slope $\sim 10 \mathrm{~K} / \mathrm{GPa}$ at pressures below $1 \mathrm{GPa}$ and to the Clapeyron slope $\sim 100 \mathrm{~K} / \mathrm{GPa}$ at pressures above $1 \mathrm{GPa}$. 